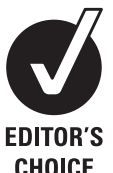

CHOICE

\section{See Editorial, page 251}

${ }^{1}$ CNR Institute of Clinical Physiology, Pisa, Italy ${ }^{2} \mathrm{G}$ Pasquinucci Hospital, G Monasterio Foundation, Massa, Italy ${ }^{3}$ Complutense University, Madrid, San Carlos University Hospital, Madrid, Spain

\section{Correspondence to}

Dr Maria Grazia Andreassi, CNR Institute of Clinical Physiology,

G Pasquinucci Hospital, Via Aurelia Sud-Montepepe, 54100 Massa, Italy; andreas@ifc.cnr.it

Accepted 28 July 2009 Published Online First 16 August 2009

\title{
Cumulative patient effective dose and acute radiation-induced chromosomal DNA damage in children with congenital heart disease
}

\author{
Lamia Ait-Ali, ${ }^{1,2}$ Maria Grazia Andreassi, ${ }^{1,2}$ Ilenia Foffa, ${ }^{1,2}$ Isabella Spadoni, ${ }^{2}$ \\ Eliseo Vano, ${ }^{3}$ Eugenio Picano ${ }^{1}$
}

\begin{abstract}
Background The seventh Committee on "Biological Effects of Ionizing Radiation" (BEIR VII, 2006) underlines "the need of studies of infants who are exposed to diagnostic radiation because catheters have been placed in their hearts".
\end{abstract}

Objective To determine the lifetime attributable risk (LAR) of cancer associated with the estimated cumulative radiological dose in 59 children (42 male, age $2.8 \pm 3.2$ years) with complex congenital heart disease, and to assess chromosomal DNA damage after cardiac catheterisation procedures.

Methods In all patients, the cumulative exposure was estimated as effective dose in milliSievert (mSv), and LAR cancer was determined from the BEIR VII report. In a subset of 18 patients (13 male, age $5.2 \pm 5.7$ years) micronucleus as a biomarker of DNA damage and longterm risk predictor of cancer was assayed before and $2 \mathrm{~h}$ after catheterisation procedures. Dose-area product $\left(\mathrm{Gy} \mathrm{cm}^{2}\right)$ was assessed as a measure of patient dose. Results The median life time cumulative effective dose was $7.7 \mathrm{mSv}$ per patient (range 4.6-41.2). Cardiac catheterisation procedures and CT were responsible for $95 \%$ of the total effective dose. For a 1-year-old child, the LAR cancer was 1 in 382 (25th to 75th centiles: 1 in 531 to 1 in 187) and 1 in 156 (25th to 75th centiles: 1 in 239 to 1 in 83) for male and female patients, respectively. Median micronucleus values increased significantly after the procedure in comparison with baseline (before $6 \%$ vs after $9 \%, p=0.02$ ). The median dose-area product value was $20 \mathrm{~Gy} \mathrm{~cm}^{2}$ (range $1-277$ ).

Conclusion Children with congenital heart disease are exposed to a significant cumulative dose. Indirect cancer risk estimations and direct DNA data both emphasise the need for strict radiation dose optimisation in children.

\section{INTRODUCTION}

Radiation can be used effectively for diagnosis and treatment, but it can also subsequently cause cancers and other conditions. ${ }^{1}$ Trends indicate that worldwide population exposure from medical radiation is increasing ${ }^{2}$ and the use of procedures with a high radiation dose continues to grow steadily, ${ }^{4-8}$ especially in cardiology ${ }^{6}$ - and particularly in paediatric cardiology. ${ }^{9}$ Children are at least four times more sensitive than adults to the induction of cancer, and the proliferation of appropriate and inappropriate examinations with high radiological dose in children has raised concern among the paediatric community $^{10}$ and regulatory bodies. ${ }^{11}{ }^{12}$ The National Academies' Biological Effects of Ionizing Radiation, 7th Report (BEIR VII, phase 2), presented to the USA Congress in June 2005 and published in 2006, underlines "the need of studies of infants who are exposed to diagnostic radiation because catheters have been placed in their hearts" among priority research needs. ${ }^{12}$

The BEIR VII report develops risk estimates for cancer from exposure to low-level ionising radiation using the most current data and epidemiological models available, providing a framework for estimating cancer risk associated with radiation exposure from medical exposure. ${ }^{12}$

The aim of our study was to determine the lifetime attributable risk of cancer (fatal and non-fatal) associated with the estimated lifetime cumulative radiological dose in children with complex congenital heart disease (CHD) by using the BEIR VII estimates.

Since these data provide only indirect populationbased estimates, we also evaluated directly whether radiation exposure during cardiac catheterisation procedures can induce chromosomal DNA damage. To this end, a micronucleus assay (MN) was performed as a biomarker of chromosomal damage and intermediate end point of carcinogenesis ${ }^{13} 14$ before and after radiation exposure.

\section{PATIENTS AND METHODS}

\section{Patients}

The patient population included 59 consecutive inpatients with complex CHD (42 male, age $=2.8 \pm 3.2$ years) who were admitted in 2007 for cardiac haemodynamic procedures to the G Pasquinucci Hospital in Massa, Italy. Exclusion criteria included the inability to obtain consent from the child's parents, and the impossibility of reconstructing an accurate history for both the type and number of radiological procedures.

Thirty-one interventional procedures were performed (10 atrioseptostomy according to Rashkind, two pulmonary branch balloon angioplasties, seven pulmonary valvuloplasties, two aortic valvuloplasties, three patent ductus arteriosus closures, one ventricular septal defect closure, six aortic coarctation balloon angioplasties).

In all patients, a detailed radiological history was also reconstructed. All available paper and electronic records of present and past hospital admissions were analysed using - as the primary source of information-the electronic data bank of our institute.

All past examinations performed outside our institute were recalled by interviewing the patients parents at the time of admission and by direct perusal of available medical records of the patient. 
Table 1 Demographic and clinical characteristics of the study population

\begin{tabular}{ll}
\hline Variable & Value \\
\hline Age, mean \pm SD, years (range) & $2.8 \pm 3.2$ \\
& $(1$ month-16 years) \\
Gender, $\mathrm{n}$ & \\
Male/female & $42 / 17$ \\
BMI, kg/m² (range) & $11.5 \pm 15(2.1-75)$ \\
Diagnosis, $\mathrm{n}$ & \\
Transposition of the great arteries ( \pm ventricular septal & 12 \\
defect) & \\
Coarctation of the aorta ( \pm ventricular septal defect) & 8 \\
Tetralogy of Fallot & 7 \\
Pulmonary stenosis & 6 \\
Functionally univentricular heart & 5 \\
Pulmonary atresia ( \pm ventricular septal defect) & 4 \\
Patent ductus arteriosus & 3 \\
Other complex CHD & 14
\end{tabular}

$\mathrm{CHD}$, congenital heart disease.

Examinations without an available record were not considered. Demographic and clinical characteristics of the studied patients are summarised in table 1. Legal representatives of patients gave their informed consent at the time of admission to grant the use of hospital data for research purposes and specifically for the bioassay study, authorised by the local ethical research committee.

\section{Indirect estimation of cumulative dose and cancer risk for radiation exposure}

For each examination the estimated effective dose in milliSievert $(\mathrm{mSv})$ was derived from average dose values reported by the peer-reviewed literature on effective dose for paediatric ionising procedures. $^{15-19}$

Representative values and ranges of the effective radiation dose for some diagnostic radiology procedures are presented in table 2 .

In order to calculate the cumulative risk of cancer, we used estimates of cancer from BEIR VII released in $2006 .^{12}$ According to these estimates, it is predicted that for a $10 \mathrm{mSv}$ effective dose in adult approximately one person in 2000 would develop fatal cancer ${ }^{11}$ and one in 1000 would develop fatal and non-fatal cancer. ${ }^{12}$ The BEIR VII report estimates that the cancer risk in children is higher than for adults. For instance, the same radiation in the first years of life for boys produces three to four times the cancer risk as exposure between the ages of 20 and $50 .{ }^{12}$

Table 2 Representative effective radiation dose, range and equivalent number of plain chest radiographs for paediatric cardiac procedures

\begin{tabular}{lll}
\hline Examination & $\begin{array}{l}\text { Effective dose, } \\
\mathbf{m S v} \text { (range) }\end{array}$ & $\begin{array}{l}\text { Chest x-rays } \\
\text { (range) }\end{array}$ \\
\hline $\begin{array}{l}\text { Conventional radiology } \\
\text { Chest x-ray (single posteroanterior) }\end{array}$ & 0.02 & 1 \\
CT & & \\
Head CT & $4(1-6)$ & $200(50-300)$ \\
Chest CT & $3(5-12)$ & $150(250-600)$ \\
Abdomen CT & $5(4-20)$ & $250(200-1000)$ \\
Interventional cardiology & & $230(30-1150)$ \\
Diagnostic catheterisation & & $300(50-1850)$ \\
Therapeutic catheterisation & $4.6(0.6-23)$ & \\
\hline
\end{tabular}

\section{Direct dose estimation and MN assay}

The $\mathrm{MN}$ cytokinesis block assay in human lymphocytes was performed on a randomly selected subset of 18 patients (13 male, age $5.2 \pm 5.7$ years) without comorbidity, and who had undergone cardiac catheterisation procedures for diagnostic purposes $(n=13)$ and for therapeutic procedures $(n=5)$.

All procedures were performed using the Philips Integris H5000C monoplane with the x-ray tube MRC 2000508 ROT GS 1001. The dose-area product (DAP) was obtained from a transmission ionisation chamber built into the collimator housing of the radiography tube. The DAP $\left(\mathrm{Gy} \mathrm{cm}^{2}\right)$ is a quantity used to estimate patient doses in fluoroscopy guided procedures and represents the dose in air measured at a given distance from the x-ray tube multiplied by the area of the x-ray beam at that distance. ${ }^{15} 2021$

The cumulative DAP for a procedure is a surrogate measurement for the total amount of x-ray energy delivered to the patient, and is considered a valid indicator of a patient's dose and consequent risk for radiation-induced effects. Effective dose was also estimated by the use of a conversion factor $\left(1.2 \mathrm{mSv} \mathrm{Gy}{ }^{-1} \mathrm{~cm}^{-2}\right)$ derived from the literature (CF=effective dose/DAP (mSv Gycm $\left.^{-2}\right)$. $^{17}$

Venous blood samples were collected at baseline and $2 \mathrm{~h}$ after the procedure. Two separate cultures from each sample were set up by mixing $0.3 \mathrm{ml}$ of whole blood with $4.7 \mathrm{ml}$ of RPMI 1640 medium; cultures were incubated at $37^{\circ} \mathrm{C}$ for $72 \mathrm{~h}$. Cytochalasin $\mathrm{B}(6 \mu \mathrm{g} / \mathrm{ml})$ was added $44 \mathrm{~h}$ after culture initiation. Cells were then harvested and fixed according to the standard method in use in our laboratory. ${ }^{14}$ For each sample, 1000 binucleated cells were scored by use of an optical microscope (final magnification $\times 400$ ) for $\mathrm{MN}$ analysis, according to the criteria for $\mathrm{MN}$ acceptance. ${ }^{22}$ We quantified the micronucleated binucleated cell frequency as the number of micronucleated cells per 1000 cells. MN frequency was evaluated by the same three microscopists who had no information as to the identity of patients.

\section{Statistical analysis}

Statistical analyses of the data were conducted with the Stat view statistical package, version 5.0.1. The average dose values of individual examinations were expressed as median and 25 th -75 th centiles. Differences were evaluated by the Mann-Whitney $U$ test. Because of the skewness of the distributions of $\mathrm{MN}$ values, analyses were performed using the logarithmic transformation of data. Results are expressed as mean $( \pm S D)$. Differences between the means of the two continuous variables were evaluated by the paired Student $t$ test. Regression analysis with the Pearson test was also used to evaluate the relationship between the two continuous variables. A $p$ value $<0.05$ was considered significant.

\section{RESULTS}

In total, 1548 procedures with ionising radiation were performed during the lifetime of the 59 patients.

On average, each patient underwent a mean of $26.2 \pm 26.3$ examinations (range $1-150,25$ th -75 th interquartile range 12-27.7). The number of each type of examinations is given in table 3 . The median life time cumulative effective dose was $7.7 \mathrm{mSv}$ per patient (range 4.6-41.2, 25th-75th centiles 5.5-12.3). The estimated median effective dose was not significantly different between male $(7.1 \mathrm{mSv}, 25 \mathrm{th}-75$ th centiles $5.1-12.5 \mathrm{mSv})$ and female $(9.4 \mathrm{mSv}, 25 \mathrm{th}-75 \mathrm{th}$ centiles 6.5-18.1 $\mathrm{mSv}$ ) patients. A positive significant correlation was found between cumulative radiological effective dose and age $(\mathrm{r}=0.518, \mathrm{p}<0.0001)$. 
Table 3 Typical effective dose from paediatric and cardiology procedures

\begin{tabular}{lll}
\hline Examination & Total number & $\begin{array}{l}\text { Number per patient, } \\
\text { mean (range) }\end{array}$ \\
\hline $\begin{array}{l}\text { Conventional radiology } \\
\text { Chest x-ray }\end{array}$ & 1432 & $25.1 \pm 25.7(1-144)$ \\
CT & & \\
Head CT & 7 & $1.0 \pm 0.6(0-2)$ \\
Chest CT & 7 & $1.2 \pm 0.4(1-2)$ \\
Interventional cardiology & & \\
Diagnostic catheterisation & 55 & $1.3 \pm 0.6(1-3)$ \\
Therapeutic catheterisation & 40 & $1.2 \pm 0.6(1-4)$ \\
\hline
\end{tabular}

Figure 1 shows the contribution of various types of medical ionising procedures to the total collective dose. Conventional $x$-ray examinations represent $93 \%$ of the total number of examinations, corresponding to only $5 \%$ of the collective effective dose. Three types of procedures were responsible for about $95 \%$ of the total collective effective dose: diagnostic catheterisation, interventional catheterisation and CT.

The corresponding estimated lifetime attributable risk of fatal cancer for all combinations of age (ranging from 0to 15 years) was 1 in 1717 and 1 in 859, for male (receiving $7.1 \mathrm{mSv}$ ) and female (receiving $9.4 \mathrm{mSv}$ ) patients, respectively.

The lifetime attributable risk (fatal and non-fatal cancer) was 1 in 804 for male subjects, and 1 in 331 for female subjects. However, risks were 1.9-2 times higher for child of 1 year than for a 15 year old.

For a 1-year-old child, the median risk of (fatal and non-fatal) cancer was 1 in 382 ( 25 th to 75 th centiles 1 in 531 to 1 in 187) and 1 in 156 (25th to 75 th centiles 1 in 239 to 1 in 83 ) for male and female patients, respectively.

For direct dose estimation in the subset of 18 patients, the median fluoroscopy time during the cardiac catheterisations was 22.8 min (range 3-34) without any significant difference between diagnostic and interventional procedures $(p=0.6)$. The mean DAP value was $45.3 \pm 64.8 \mathrm{~Gy} \mathrm{~cm}^{2}$ with a median of $20 \mathrm{~Gy} \mathrm{~cm}^{2}$ and a $25 \mathrm{th}-75 \mathrm{th}$ interquartile range of $12-64 \mathrm{~Gy} \mathrm{~cm}^{2}$.
Median effective DAP values were found to be significantly higher in therapeutic interventions than in diagnostic procedures (93 Gy $\mathrm{cm}^{2}$ vs $14 \mathrm{~Gy} \mathrm{~cm}^{2}, \mathrm{p}=0.005$ ). DAP values for all patients studied are presented in table 4 . The highest value of DAP dose delivered was found for an interventional procedure involving one aortic coarctation balloon angioplasty $\left(277 \mathrm{~Gy} \mathrm{~cm}^{2}\right)$.

The median effective MN value was $6 \%$ o $(25 \mathrm{th}-75$ th interquartile range $4-7 \%$ ) at baseline and showed a significant rise at $2 \mathrm{~h}$ with a median of $9 \%$ (25th-75th interquartile range $8-11 \%$ ) after procedures (Figure 2). Median $\mathrm{MN}$ values were higher than the baseline values for both diagnostic $(7 \%$ vs $11 \%, \mathrm{p}=0.02)$ and therapeutic cardiac catheterisation procedures $(5 \%$ vs $9 \%$, $\mathrm{p}=0.03$ ). However, we did not observe any relationship between DAP and $\% \mathrm{MN}$ increase $(\mathrm{r}=0.1, \mathrm{p}=0.74)$, even after taking into account the patient's weight $(r=0.1, p=0.6)$.

\section{DISCUSSION}

The average present-day child with CHD is exposed to a significant cumulative radiological effective dose. The new generation of patients with CHD benefits from the enormous advances in cardiac imaging and interventional cardiology, but also receives an unprecedented radiological exposure, associated with a significant long-term risk of cancer based on the latest risk estimates.

\section{The rise of imaging testing in children}

We are witnessing a spectacular rise in the potential and versatility of cardiovascular imaging in children. The use of multislice CT is increasing even faster in children than in adults, presumably because of the big advantage of a short exposure time that allows for its use without a sedative. ${ }^{3}$ It is estimated that there were at least 6.5 million CT examinations in the USA in the paediatric age band in the year 2006, corresponding with about $15 \%$ of all CT examinations. ${ }^{5}$ Nuclear cardiology stress testing in children is performed in $30 \%$ of US institutions, according to a recent survey of the AHA-ACC. ${ }^{23}$ The Spanish Society of Cardiology has published data on paediatric cardiology ${ }^{24}$ showing increases in the number of fluoroscopic procedures over the years 2000-4 of between $21 \%$ (for dilatation) to $97 \%$ (for embolisations).

Figure 1 The most frequent examinations and total collective dose in congenital heart disease: relative contribution of conventional radiographs, $\mathrm{CT}$, diagnostic catheterisation and interventional radiology to $(A)$ the frequency and $(B)$ the total collective effective dose.

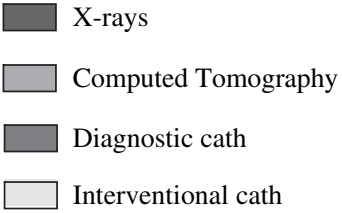

A

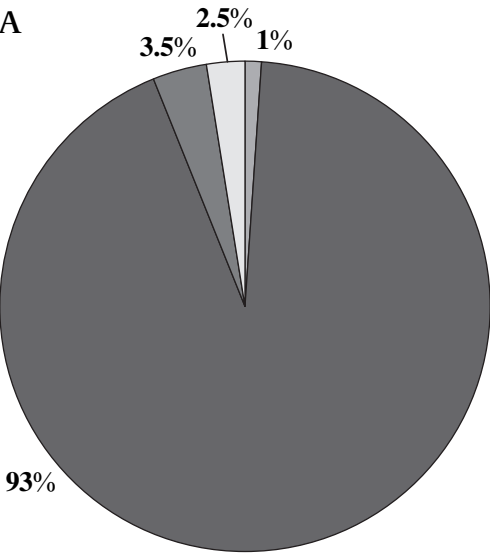

B

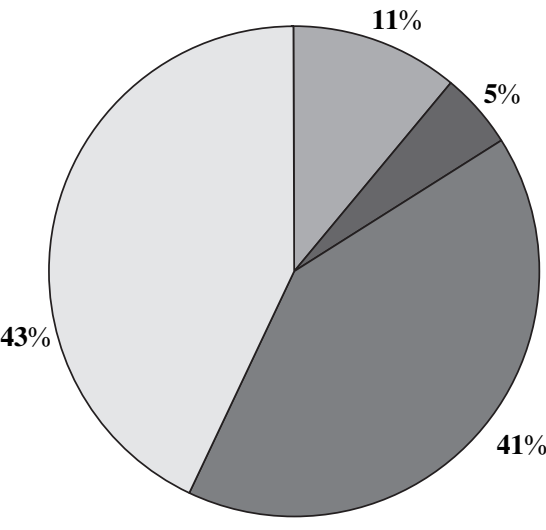

Total collective dose 
Table 4 Patient dose for diagnostic and therapeutic catheterisation procedures

\begin{tabular}{llrrlc}
\hline Type of procedure & Gender & $\begin{array}{l}\text { Age, } \\
\text { months }\end{array}$ & $\begin{array}{l}\text { Weight, } \\
\text { kg }\end{array}$ & $\begin{array}{l}\text { Fluoroscopy } \\
\text { time, min }\end{array}$ & $\begin{array}{l}\text { DAP } \\
\text { Gy } \mathbf{c m}^{2}\end{array}$ \\
\hline Diagnostic & M & 5 & 4.9 & 30 & 7 \\
Stent implantation & M & 168 & 57.0 & 25 & 277 \\
Diagnostic & $\mathrm{F}$ & 36 & 12.4 & 26 & 20 \\
Diagnostic & $\mathrm{F}$ & 1 & 2.9 & 23 & 6 \\
Diagnostic & $\mathrm{M}$ & 6 & 9.4 & 3 & 1 \\
Balloon valvuloplasty & $\mathrm{M}$ & 4 & 4.2 & 24 & 12 \\
Diagnostic & $\mathrm{M}$ & 8 & 6.7 & 34 & 14 \\
Stent implantation & $\mathrm{F}$ & 168 & 58.0 & 19 & 64 \\
Stent implantation & $\mathrm{F}$ & 192 & 75.0 & 13 & 99 \\
Diagnostic & $\mathrm{M}$ & 96 & 23.8 & 17 & 20 \\
Diagnostic & $\mathrm{M}$ & 132 & 37.0 & 30 & 65 \\
Diagnostic & $\mathrm{M}$ & 24 & 12.5 & 20 & 14 \\
Diagnostic & $\mathrm{M}$ & 6 & 5.0 & 27 & 12 \\
Stent implantation & $\mathrm{M}$ & 120 & 27.7 & 26 & 93 \\
Diagnostic & $\mathrm{F}$ & 48 & 29.0 & 19 & 35 \\
Diagnostic & $\mathrm{M}$ & 8 & 7.0 & 25 & 14 \\
Diagnostic & $\mathrm{M}$ & 96 & 25.2 & 28 & 35 \\
Diagnostic & $\mathrm{M}$ & 5 & 6.0 & 21 & 28 \\
\hline
\end{tabular}

DAP, dose-area product.

Catheterisation procedures in children are typically more time consuming than adult procedures. ${ }^{18}$ For several reasons, procedures are longer in children, especially infants, because many patients have had previous studies and have limited access site; in infants the vessels are smaller and more difficult to cannulate; multiple angiograms in several cardiac chambers, using different views, are often needed.

\section{Special problems of medical radiation in children}

The growing use of interventional and non-invasive imaging with ionising radiation in children represents a tremendous benefit for the diagnosis and treatment of small patients. However, there are special problems in children that one may wish to consider. First, for any given dose children are three-tofour times more sensitive than adults to the induction of cancer as they have more rapidly dividing cells than adults and have longer life expectancy. ${ }^{13} 1112$ Second, for a given procedure, the effective dose is larger in a small infant than in an adult: organs are closer together in small children, resulting in more radiation dose to nearby organs when the area of interest is being imaged. ${ }^{111} 12$ Third, in paediatric cardiology, radiological proce-

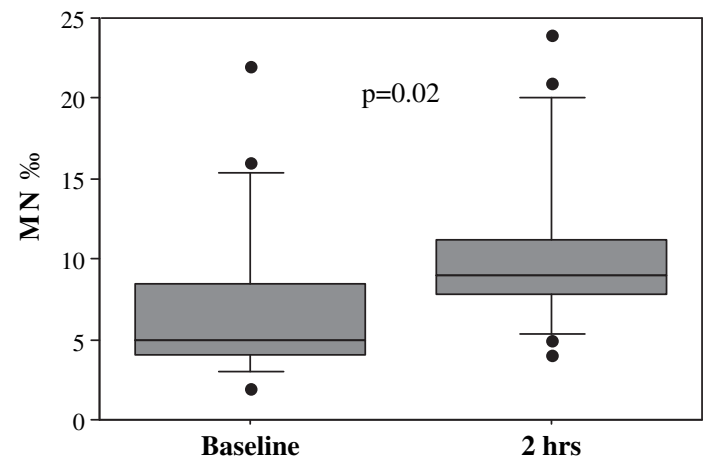

Figure 2 Box-and-whiskers plot of micronuclei number before and $2 \mathrm{~h}$ after radiation exposure in the overall population. Median and $25-75$ th centiles are shown for each group. Values above the 90th centile and below the 10th centile (outliers) have been separately plotted (as circles). MN, micronucleus. dures are practised and/or prescribed by cardiologists, who may sometimes have suboptimal awareness of doses and risks ${ }^{25}$ owing to lack of adequate formal radiation training ${ }^{26}$-although it is also true that even radiologists may substantially underestimate radiation doses and risks. ${ }^{27}$ Fourth, cardiological examinations deliver the highest organ dose from CT and interventions ${ }^{28} 29$ to lung and breast. In particular, during a cardiac CT the breast dose is about 10 times higher than with cardiac interventional procedures. Recent ICRP 2007 documents ${ }^{30}$ left virtually unchanged the whole-body risk estimates, but raised the breast risk factor (ie, the excess probability of fatal cancer) by $210 \%$, from 40 in 1000000 per mSv in ICRP 1991 to 124 in 1000000 per $\mathrm{mSv}$ in ICRP 2007. ${ }^{30}$ The same document also raised, albeit less markedly, the lung risk factor by 33\%, from 85 to 113 in 1000000 per $\mathrm{mSv}$. Although these estimates are clouded by a certain degree of uncertainty in the low-dose range, the epidemiological data ${ }^{31}$ in children exposed to medical radiation corroborate the assumption of all major organisations that even low doses can harm the patient, and no safe dose exists. ${ }^{12}$

Comparison with previous radiological and biodosimetric studies In our patients the main contribution to dose was from interventional procedures and CT $(84 \%$ and $11 \%$ of the average dose, respectively). This picture is broadly consistent with recent data on sources of irradiation for the "average" (non-cardiological) patient ${ }^{5}$ and on adult cardiological patients. ${ }^{32}$ Our data are also in agreement with the preliminary data presented by the European Heart Survey, which reported an annual effective dose of $0.46 \mathrm{mSv} /$ year in the follow-up of these patients, with about $80 \%$ of the dose coming from CT and angiography. ${ }^{33}$

Chromosome aberrations in circulating lymphocytes are an intermediate end point of carcinogenesis and a long-term predictor of cancer, ${ }^{13} 14$ and increased a few hours after a fluoroscopic cardiac procedure in children was reported, in a pioneering study conducted in 1978 by Adams et al. ${ }^{34}$ Young adolescents with repaired CHD who were exposed to low-dose diagnostic ionising radiation at age $<1$ year, have an up to threefold increase in chromosomal aberrations in circulating lymphocytes decades after the exposure. ${ }^{14}$ In our study, the indirect population-based estimates of cumulative dose and cancer risk were corroborated by direct measurements of $\mathrm{MN}$ increase in a subset of patients. The increase was obvious and consistent, although with substantial variability probably owing to genetic differences in polymorphisms of genes involved in DNA damage and/or repair and an environmental oxidant-antioxidant milieu. ${ }^{35}$ This approach provides a direct documentation of radiation genotoxicity and may clear the pathway to individually tailored radiation-sparing or chemopreventive strategies.

\section{Study limitations}

The number of patients is relatively small, but they are consecutive and representative of the spectrum of clinical situations met in a contemporary paediatric cardiology and cardiac surgery. An undoubted limitation of our study is that the lifetime radiological history was derived from hospital records, when available, and from patient history. This leads unavoidably to an approximation, and possibly to an underestimation, of the total radiological burden.

Another limitation is that there is in the real world a marked variability in the dose of each examination. ${ }^{36}$ This variability is highest for interventional procedures. For instance, a percutaneous procedure of closure of patent ductus arteriosus is associated with an average effective dose corresponding to $7.6 \mathrm{mSv}$, but the individual procedure value may range between 2.1 and 
$36 \mathrm{mSv}^{4} 3738$ Both these aspects - the recall bias and the adoption of typical dose values from the literature rather than true measured values - might have affected the precision of individual patient dose estimation, but are unlikely to substantially affect the order of magnitude of observed values. In addition, we integrated the history-based approach, based upon indirect assessment of doses and population-based estimates of risks, with a direct, patient-based, individual assessment of patient dose and of acute radiation damage through direct biodosimetry with $\mathrm{MN}$ assay and faithful radiation dose measurement with DAP. The two approaches are conceptually complementary and seem to point in the same direction, indicating that potentially oncogenic radiation-induced damage is not negligible in these children.

\section{Clinical implications: justify and optimise}

Although the benefits of imaging are immense, it is also possible that not all these examinations are entirely appropriate and that there is a suboptimal management of radiological doses (and long-term cancer risks) in everyday clinical practice of paediatric cardiology. The radiation concern is particularly important in our patients with CHD for three reasons. First, adult grown-up patients with surgically repaired $\mathrm{CHD}$ are a large and growing population, estimated to be one million in US in the year 2000, compared with an estimated 300000 in 1980, and 1.4 million are expected by $2020 .{ }^{39}$ Second, the long-term outcome of the underlying cardiac disease has been dramatically improved by interventions in the past decade, and now excellent long-term survival is the rule, rather than the exception. ${ }^{910}$ Third, and most importantly, children are several times more sensitive to radiation than middle-aged adults. ${ }^{1} 31112$ Therefore, when managing today a serious condition such as a complex CHD, we have also to protect the patient from risks that may become clinically manifest after years and even decades. We should justify the indication and optimise the dose delivery, adjusting doses, reducing multiple scans with contrast material and eliminating inappropriate referrals.

For instance, the application of currently available dosereduction techniques for heart scan and invasive cardiology could be strongly applied in daily practice in order to allow a reduction of patient doses while maintaining the image quality. ${ }^{40}$ These practice patterns were recommended by the FDA, the European Union referral guidelines for imaging and by the recent white paper of the American College of Radiology. ${ }^{42}$ In Europe the justification, optimisation and responsibility principles are also reinforced by the Euratom law. ${ }^{43}$ The challenge ahead is to implement these recommendations universally in clinical practice.

Competing interests None.

Ethics approval This study was conducted with the approval of the local ethical research committee.

Provenance and peer review Not commissioned; externally peer reviewed.

\section{REFERENCES}

1. United Nations Scientific Committee on the Sources and Effects of lonising Radiation. Report on the effects of atomic radiation to the general assembly, 2000. Medical radiation exposures. New York: United Nations, 2001.

2. Picano E. Sustainability of medical imaging. BMJ 2004;328:578-80.

3. Hall EJ. Lessons we have learned from our children: cancer risks from diagnostic radiology. Pediatr Radiol 2002;32:700-6.

4. Vano $\mathbf{E}$, Faulkner K. ICRP special radiation protection issues in interventional radiology, digital and cardiac imaging. Radiat Prot Dosimetry 2005;117:13-17.

5. Brenner DJ, Hall EJ. Computed tomography-an increasing source of radiation exposure. N Engl J Med 2007:357:2277-84.

6. Togni M, Balmer F, Pfiffner D, et al. Percutaneous coronary intervention in Europe 1992-2001. Eur Heart J 2004;25:1208-13.
7. Lucas FL, DeLorenzo MA, Sievers AE, et al. Temporal trends in the utilization of diagnostic testing and treatments for cardiovascular disease in the United States, 1993-2001. Circulation 2006;113:374-9.

8. Ayanian JZ. Rising rates of cardiac procedures in the United States and Canada. Too much of a good thing? Circulation 2006;113:333-5.

9. Patel HT, Hijazi ZM. Pediatric catheter interventions: a year in review 2004-2005. Curr Opin Pediatr 2005;17:568-73.

10. Justino H. The ALARA concept in pediatric cardiac catheterization: techniques and tactics for managing radiation dose. Pediatr Radiol 2006:36:146-53.

11. International Commission on Radiation Protection: Radiation and Your Patient: a Guide for Medical Practitioners. A web module produced by committee 3 of the International commission on radiological protection 2001. http:// www.icrp.org/docs/Rad_for_GP_for_web.pdf. (accessed 27 July 2008).

12. Committee to Assess Health Risks from Exposure to Low Levels of Ionizing Radiation; Nuclear and Radiation Studies Board, Division on Earth and Life Studies, National Research Council of the National Academies. Health risks from exposure to low levels of ionizing radiation: BEIR VII Phase 2. Washington, DC: The National Academies Press, 2006.

13. Bonassi S, Znaor A, Ceppi M, et al. An increased micronucleus frequency in peripheral blood lymphocytes predicts the risk of cancer in humans. Carcinogenesis 2007:28:625-31.

14. Andreassi MG, Ait-Ali L, Botto N, et al. Cardiac catheterization and long-term chromosomal damage in children with congenital heart disease. Eur Heart $\mathrm{J}$ 2006:27:2703-8.

15. Boothroyd A, McDonald E, Moores BM, et al. Radiation exposure to children during cardiac catheterization. Br J Radiol 1997:70:180-5.

16. Moore JD, Shim D, Sweet J, et al. Radiation exposure to children during coil occlusion of the patent ductus arteriosus. Catheter Cardiovasc Interv 1999:47:449-54.

17. Bacher $\mathbf{K}$, Bogaert $\mathrm{E}$, Lapere $\mathrm{R}$, et al. Patient-specific dose and radiation risk estimation in pediatric cardiac catheterization. Circulation 2005;111:83-9.

18. Martinez LC, Vano E, Gutierrez F, et al. Patient doses from fluoroscopically guided cardiac procedures in pediatrics. Phys Med Biol 2007;52:4749-59.

19. Brody AS, Frush DP, Huda W, et al. Radiation risk to children from computed tomography. Pediatrics 2007:120:677-82.

20. Betsou S, Efstathopoulos EP, Katritsis D, et al. Patient radiation doses during cardiac catheterisation procedures. Br J Radiol 1998;71:634-9.

21. Hirshfeld JW Jr, Balter S, Brinker JA, et al. ACCF/AHA/HRS/SCAl clinical competence statement on physician knowledge to optimize patient safety and image quality in fluoroscopically guided invasive cardiovascular procedures: a report of the American College of Cardiology Foundation/American Heart Association/American College. Circulation 2005;111:511-32.

22. Fenech M. Optimisation of micronucleus assays for biological dosimetry. In: Gledhill BL, Mauro F, eds. New horizons in biological dosimetry. New York: Wiley, 1981:373-6.

23. Rodgers GP, Ayanian JZ, Balady G, et al. A report of the American College of Cardiology/American Heart Association/American College of Physicians-American Society of Internal Medicine Task Force on Clinical. Circulation 2000;102:1726.

24. López-Palop R, Moreu J, Fernández-Vázquez F, et al. [Spanish Cardiac Catheterization and Coronary Intervention Registry. 14th official report of the Spanish Society of Cardiology Working Group on Cardiac Catheterization and Interventional Cardiology (1990-2004)] (In Spanish.). Rev Esp Cardiol 2005;58:1318-34.

25. Correia MJ, Hellies A, Andreassi MG, et al. Lack of radiological awareness among physicians working in a tertiary-care cardiological centre. Int J Cardio/ 2005;103:307-11

26. Vano E, Gonzalez L, Fernandez JM, et al. Occupational radiation doses in interventional cardiology: a 15-year follow-up. Br J Radiol 2006;79:383-8.

27. Lee CI, Haims AH, Monico EP, et al. Diagnostic CT scans: assessment of patient, physician, and radiologist awareness of radiation dose and possible risks. Radiology 2004;231:393-8

28. Zanzonico $\mathbf{P}$, Rothenberg LN, Strauss HW. Radiation exposure of computed tomography and direct intracoronary angiography: risk has its reward. J Am Coll Cardiol 2006;47:1846-9.

29. Einstein AJ, Henzlova MJ, Rajagopalan S. Estimating risk of Cancer associated with radiation exposure from 64-slice Computed Tomography Coronary Angiography. JAMA 2007;298:317-23.

30. International Commission on Radiation Protection. Recommendations of the International Commission on Radiological Protection. ICRP publication 103. Ann ICRP 2007:37:1-332.

31. Kleinerman RA. Cancer risks following diagnostic and therapeutic radiation exposure in children. Pediatr Radiol 2006;36:121-5.

32. Bedetti G, Botto N, Andreassi MG, et al. Cumulative patient effective dose in cardiology. Br J Radiol 2008;81:699-705.

33. Hoffmann A, Engelfriet $P$, Mulder B. Radiation exposure during follow-up of adults with congenital heart disease. Int J Cardiol 2007:118:151-3.

34. Adams FH, Norman A, Bass D, et al. Chromosome damage in infants and children after cardiac catheterization and angiocardiography. Pediatrics 1978;2:312-6.

35. Au WW. Heritable susceptibility factors for the development of cancer. J Radiat Res 2006;47(Suppl B):13-17.

36. Einstein A. Radiation risk from coronary artery disease imaging: how do different diagnostic tests compare? Heart 2008:94:1519-21.

37. Kocinaj D, Cioppa A, Ambrosini G, et al. Radiation dose exposure during cardiac and peripheral arteries catheterisation. Int J Cardiol 2006:113:283-4.

38. Neofotistou V, Vano E, Padovani R, et al. Preliminary reference levels in interventional cardiology. Eur Radiol 2003;13:2259-63. 
39. Brickner ME, Hillis LD, Lange RA. Congenital heart disease in adults. First of two parts. N Engl J Med 2000;342:256-63.

40. Kuon E. Radiation exposure in invasive cardiology. Heart 2008:94:667-74.

41. Rixe J, Conradi G, Rolf A, et al. Radiation dose exposure of computed tomography coronary angiography - comparison of dual source-, 16 -slice and 64-slice - CT. Heart 2009:95:1337-42. doi: 10.1136/hrt.2008.161018.
42. Amis ES Jr, Butler PF, Applegate KE, et al. American College of Radiology white paper on radiation dose in medicine. J Am Coll Radiol 2007;4:272-84.

43. Council Directive $97 / 43 /$ Euratom of 30 June 1997 on health protection of individual against the dangers of ionizing radiation in relation to medical exposure, and repealing Directive 84/466/Euratom. Official Journal of the European Communities $L$

$1997 \cdot 180 \cdot 22-7$. 